\title{
Greedy approach for solving the capacitated vehicle routing problem of liquefied natural gas distribution to power plants
}

\author{
$A P A$ Wijharnasir ${ }^{*}, M A$ Alghasi $^{2}$, and $N$ Pujawan $^{1}$ \\ ${ }^{1}$ Department of Technology Management, Sepuluh Nopember Institute of Technology, Surabaya, \\ Indonesia \\ ${ }^{2}$ School of Petroleum Engineering, University of New South Wales, Sydney, Australia
}

\begin{abstract}
In LNG industries, how to decide the number of ships and their routes for transporting LNG to every demand location efficiently effects the minimization of total operational cost. Therefore, this paper provides a case study in Papua and proposes a model to determine the optimum ship route to transport LNG from an LNG production terminal to thirteen regasification terminals by considering both transportation cost and inventory cost. Distance, power plants demands, transportation cost, and inventory cost were further analyzed by using the greedy approach. In addition, the ship sizes were limited to four alternatives, which were 2500 $\mathrm{m} 3,7500 \mathrm{~m} 3,10000 \mathrm{~m} 3$, and $23000 \mathrm{~m} 3$. The result recommends the utilization of smaller size vessels with more frequent shipments compared to the earlier research on the same case study. It considers that the result will be more adaptable for changing water depth due to changing tides at particular ports.
\end{abstract}

\section{Introduction}

Vehicle Routing Problem (VRP) is a term used to classify the problems in which a set of routes of a fleet of vehicles based at one or several depots must be determined for a number of destinations. In the literature, VRP is commonly defined under certain capacity constraints. Hence, VRP was developed to another term called Capacitated Vehicle Routing Problem (CVRP). Over the past decades, many literatures [1, 2, 3, 4] have been intensively studying either heuristic or metaheuristic method as an approach to find the solution regarding the CVRP. Due to the fact that it is difficult to achieve an optimal solution with a traditional optimization method, there are many heuristic or metaheuristic approaches that had been developed to overcome this barrier [1]. The heuristic algorithm, or simply called as a heuristic, is utilized to solve a particular optimization problem. Additionally, heuristic is an attempt to find sufficiently acceptable solutions instead of just finding the most optimum solution.

In classical VRP, the cost is only related to transportation cost, thus finding the shortest path and minimizing the number of vehicles lead to the solution [1]. However, inventory

\footnotetext{
* Corresponding Author: putri@mhs.mmt.its.ac.id
} 
cost also plays a dominant role. The inventory cost in LNG receiving terminal is considered as the main variable in determining the capital investment since LNG handling equipment is typically expensive. Therefore, reducing inventory cost will give a significant impact in determining capital investment.

In this research, the inventory cost will be considered. The case study in Papua is selected in response to the increasing electricity consumption in Papua that leads to the increasing of LNG demand. There is one liquefaction plant (depot) which must be connected to thirteen ports (destinations) in order to meet LNG demand of each port. Furthermore, this research is an improvement to the former research on the same case study [5]. The objective of this distribution planning is to find a set of routes to distribute the demanded LNG at the minimum cost, both for transportation and inventory cost, and evaluating its profitability by assigning certain ships to the selected set of routes.

\section{Methodology}

The model in this paper is developed systematically. Firstly, the problems, including parameters and variables, are identified. Secondly, they are causally linked with each other in a causal loop diagram. Thirdly, the problems are presented as mathematical equations by determining the parameters, variables, objective function, and constraints. Fourthly, they are configured by using a greedy approach to approximate the solution heuristically. Finally, the solution will be assessed economically by considering net present value (NPV), payback period (PBP), and return on investment (ROI) [6]. NPV was used to decide whether the project is feasible. PBP was used to indicate the time to recover the invested money, and ROI was utilized to measure the amount of the return relative to the investment.

\subsection{Causal linkages}

The variables and parameters are casually linked with arrows and labeled with plus $(+)$ and minus (-) signs. The plus sign $(+)$ indicates that one parameter correlates with the others. Otherwise, the minus sign (-) is used. This causal loop diagram eases the mathematical model construction.

\subsection{Mathematical model}

The development of this mathematical model refers to a model developed by Kir [1] with some adjustments to the constraints in order to conform with the problem, which attempts minimum total cost for distributing LNG in this case study.

\subsubsection{Sets}

$C \quad$ set of ship capacity as constraints

$R \quad$ set of nodes which defined as routes

$R_{S} \quad$ set of feasible pair of nodes taken from saving matrix step

$g \quad$ start nodes consist of production terminals and receiving terminals $(g \cup\{i, j, k, l \ldots\})$

$h \quad$ end nodes consist of LNG receiving terminals where $h \cup\{i, j, k, l \ldots\}$

$g \neq h$ and $C_{1 \leq n \leq t}=\{2500,7500,10000,23000\}$

\subsubsection{Parameters}

$d_{h} \quad$ demands at receiving terminals

$D$ total demands of a set of $\mathrm{LNG}$ receiving terminals

$m \quad$ LNG selling price 
$n \quad$ code number of route

$P \quad$ net revenue from the project

$r \quad$ feasible route

$v \quad$ ship velocity

$T R V_{g h}$ turn round voyage (round trip) from $g$ (start nodes) to $h$ (end nodes)

\subsubsection{Variables}

A LNG capacity in each vehicle if LNG is distributed between nodes

$I_{g h} \quad$ inventory cost in $h$ if LNG is distributed from $g$ (start nodes) to $h$ (end nodes)

$S$ revenue

$T_{g h} \quad$ transportation cost for a round trip to distribute LNG from $g$ to $h$

$x_{g h}=\left\{\begin{array}{c}1, \text { if the vehicle moves from } g \text { to } h \\ 0, \text { if the vehicle does not move from } \mathrm{g} \text { to } \mathrm{h}\end{array}\right.$

$\delta_{g i}=\left\{\begin{array}{l}1, \text { if } T R V \leq 8 \\ 0, \text { if } T R V>8\end{array}\right.$

$Z_{\delta g h} \quad$ every $x_{g h}$ with $\delta_{g h}=1$

$C_{n} \leq A \leq C_{n+1}$

\subsubsection{Objective function}

$$
\operatorname{MaxP}=\sum_{r \in R} S_{\mathrm{r}}-\sum_{r \in R^{T_{r}}-\sum_{r \in R} I_{r}}
$$

\subsubsection{Constraints}

$$
\begin{gathered}
S_{r}=\mathrm{d}_{h} m_{r} \quad \forall h, \forall r \in R \\
T_{r}=T_{g h} x_{g h} \quad \forall g, h_{g \neq h}, \forall r \in R \\
I_{r}=I_{g h} x_{g h} \forall g, h_{g \neq h}, \forall r \in R \\
R_{s}=\left\{Z_{\delta g h}\right\} \forall g, h_{g \neq h}, \forall \delta_{g h}=1 \\
R=\left\{R_{S}\right\} \\
A_{n}=d_{i j}+d_{j k} \forall i, j, k_{i \neq j \neq k} \\
p(i)=f(i j)\left[\sum_{i=1, j=1, i \neq j}^{n} f(i j)\right]^{-1}
\end{gathered}
$$

The objective function which is defined in equation (1), aims to maximize net revenue during a certain time. The constraints (2), (3), and (4) state the functions to calculate revenue, transportation cost, and inventory cost. The constraint (5) defines that $R_{s}$ are taken from $Z_{\delta i j}$. The constraint (6) states that a set of nodes from $R$ shall be member of $R_{s}$. Then, the constraint (7) defines that the ship capacity was calculated by summing demands at every nodes in a route. Lastly, the constraint (8) states equation for roulette wheel selection.

\subsection{Heuristic Method}

The mathematical model can be only be used for a small-scale CVRP because it would be difficult to solve more complex problems within a reasonable time. Consequently, a heuristic method was proposed to solve the problem within a reasonable time in this case study. Therefore, the greedy approach was determined to become the main approach in the algorithm. This heuristic method is desirable in finding a solution which is the best approximation of the most optimal solution within a reasonable time and in simplifying the algorithm to solve the problem.

It is elaborated in several steps by figure 1 and figure 2: 


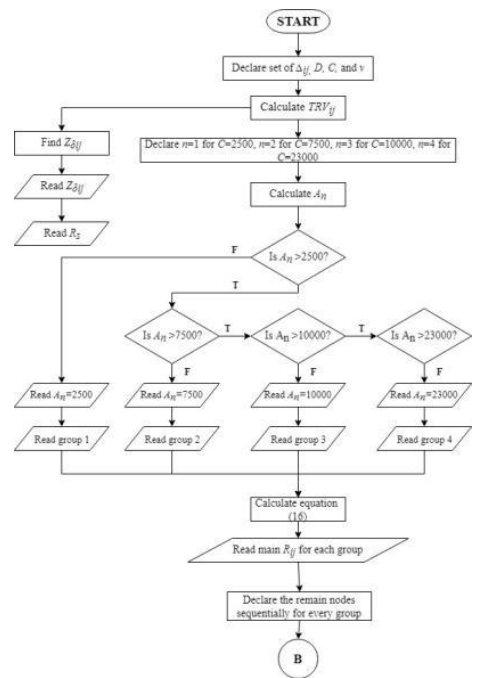

Fig. 1. Heuristic flowchart A.

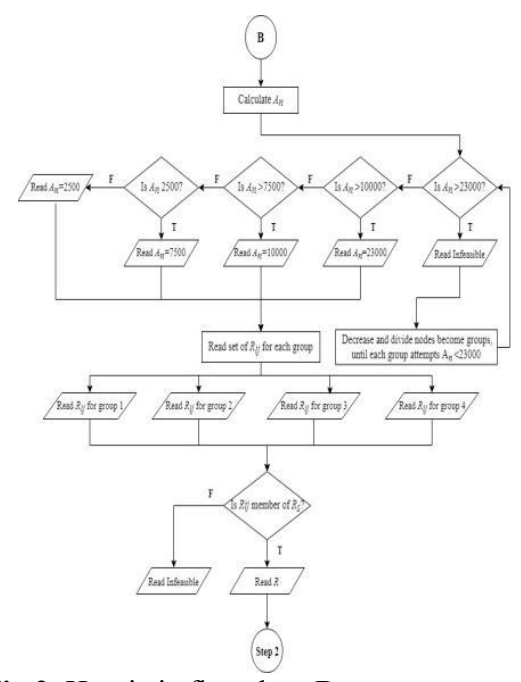

Fig.2. Heuristic flowchart B.

Due to that process, each group has a set of feasible solutions $R$ by maximizing the ship utilization. Nevertheless, to minimize transportation cost and inventory cost, a better solution will be sought by reducing the ship capacity in these orderly stages in step 2 .

Stage 1: Declare $R$ and check the possibility to decrease node by considering $A_{n}$ and $\Delta_{i j}$ for each group.

Stage 2: Calculate $A_{n}, T_{g h}$ and $I_{g h}$, then declare as $R$ option $n$ for each group.

Stage 3: Recheck whether it is possible to decrease node in order to attempt minimum $A_{n}$ for every $R$. Repeat stage 2 and declare a set of $R$ from this stage as $R$ option $n+1$.

Stage 4: Calculate total cost by summing $T_{g h}$ and $I_{g h}$ for every $R$ option $n$ in each group.

Stage 5: Find $R$ option $n$ with minimum total cost for each group. Declare 4 kinds of $R$ option $n$.

Stage 6: Find $R$ option $n$ with minimum total cost from stage 5. Declare as the new $R$.

\subsubsection{Economic assessment}

In this paper, PBP is used as a measure of the attractiveness of capital budgeting investment. The project will be assessed by NPV approach. The discount rate will be used in iteration.

The annual cash flow was calculated by subtracting the revenue with the annual operational cost, depreciation, and tax. The revenue was calculated by defining the profit margin $p m$ (in USD) $=\{1.5,2,2.5, \ldots, 4\}$. Then, a profit margin used in a case where NPV > 0 was utilized as the profitability measure for the project.

\section{Results}

The feasible solution $R$ with the cheapest total cost among them is considered as the particular solution for this case study. Referring to the solutions, every vessel is assigned to the particular route and dedicated to meet its demand. Every route is a closed-loop started from Tangguh production terminal which labeled by zero (0). The total cost is the estimated result, resulted by considering both capital and operational cost to fulfill LNG demands for 
the particular route within 20 years, as an estimated project lifetime. The detail solution is shown in table 1.

Table 1. Set of adequate routes.

\begin{tabular}{|c|c|c|c|c|c|c|c|c|c|}
\hline Vessel & $\begin{array}{c}\text { Capacity } \\
\left(\mathrm{m}^{3}\right)\end{array}$ & Route & $\begin{array}{c}\text { TRV } \\
(\text { days })\end{array}$ & $\begin{array}{c}\text { Total } \\
\text { Cost }\end{array}$ & Vessel & $\begin{array}{c}\text { Capacity } \\
\left(\mathrm{m}^{3}\right)\end{array}$ & Route & $\begin{array}{c}\text { TRV } \\
(\text { days })\end{array}$ & $\begin{array}{c}\text { Total } \\
\text { Cost }\end{array}$ \\
\hline Ship 1 & 7500 & $\begin{array}{c}0-3- \\
11-10-\end{array}$ & 8 & $\begin{array}{c}\$ 2,838 \\
573,9\end{array}$ & Ship 5 & 7500 & $0-6-0$ & 5 & $\$ 2,255,5$ \\
\hline Ship 2 & 23000 & $\begin{array}{c}0-5- \\
13-7-0\end{array}$ & 8 & $\begin{array}{c}\$ 7,743 \\
, 395,0\end{array}$ & Ship 6 & 2500 & $0-8-0$ & 6 & $\$ 1,677,4$ \\
\hline Ship 3 & 23000 & $0-4-0$ & 7 & $\begin{array}{c}\$ 15,81 \\
1,998,\end{array}$ & Ship 7 & 7500 & $0-4-0$ & 5 & $\$ 3,680,4$ \\
\hline Ship 4 & 7500 & $\begin{array}{c}0-2- \\
12-9-0\end{array}$ & 4 & $\begin{array}{c}\$ 4,137 \\
, 970,9\end{array}$ & \multicolumn{7}{|c|}{ TOTAL INVESTMENT } & $\begin{array}{c}\$ 38,145, \\
358,513 .\end{array}$ \\
\hline
\end{tabular}

As a consequence to the utilization of smaller ship capacity, the ship is easier to berth at the port during uncertain weather. The uncertain weathers leads incapabilities of large-size ship's draught to cope with uncertain sea depth. Thus, the small-size ship is adequate to be used in Indonesia, since Indonesia port condition is constantly changing due to its geographical condition. The solution is considered to be more reliable to cope with uncertain weathers at some ports in Papua.

In this case study, profit margins are iterated among the defined set. Firstly, USD 1.5 is set as the initial profit margin. However, it leads to a result of 19 years for PBP. Additionally, the NPV $<0$ simply means that the first scenario cash flow is not attractive. Secondly, USD 2.00 was taken for another scenario. The result shows PBP value is 10 years which means by applying this scenario, the payback will be achieved after 10 years. Referring to the NPV value, this scenario is more attractive to be applied since NPV $>0$ which means a feasible condition is acquired. Besides, by iterating other profit margins, the payback period will be accelerated. Moreover, the greater profit margin the greater NPV will be achieved, means that the project becomes more profitable. Nevertheless, the profit margin is decided by the company in order to accomplish higher profit.

On the other hand, references [5] stated that minimum profit margin to achieve NPV $>$ 0 in order to meet a feasible condition in this case study is USD 4.00. Whereas, by enhancing the method in this research, the minimum profit margin to meet feasible condition is USD 2.00 (refer to table 2), 50\% smaller than the earlier research done by [5]. This research proposed smaller-size ship than the earlier research with smaller value of profit margin to meet feasible solution, which means the smaller size ship utilization offers more profit for this case study. Furthermore, referring to [7], when the small amounts of LNG demands dispersed geographically far from each other (e.g., LNG distribution in Indonesia), it will be more efficient to utilize small-size ship. Finally, the economic assessment's result proved this line by offering more profit in this case study than the earlier research.

Table 2. Result of Economic Assessment

\begin{tabular}{|c|c|c|c|c|c|c|c|}
\hline $\begin{array}{c}\text { Margin } \\
(\text { USD) }\end{array}$ & $\begin{array}{c}\text { PBP } \\
\text { years) }\end{array}$ & NPV (USD) & ROI & $\begin{array}{c}\text { Margin } \\
\text { (USD) }\end{array}$ & $\begin{array}{c}\text { PBP } \\
\text { (years) }\end{array}$ & NPV (USD) & ROI \\
\hline $\mathbf{1 . 5}$ & 19 & $\$(137,592,353.61)$ & $5.31 \%$ & $\mathbf{3}$ & 5 & $\$ 324,785,596.62$ & $20.42 \%$ \\
\hline $\mathbf{2}$ & 10 & $\$ 16,533,629.80$ & $10.35 \%$ & $\mathbf{3 . 5}$ & 4 & $\$ 478,911,580.02$ & $25.46 \%$ \\
\hline $\mathbf{2 . 5}$ & 7 & $\$ 170,659,613.21$ & $15.38 \%$ & $\mathbf{4}$ & 4 & $\$ 633,037,563.43$ & $30.49 \%$ \\
\hline
\end{tabular}




\section{Conclusion}

In this paper, a greedy approach as a heuristic method is presented to solve the LNG capacitated vehicle routing problem in LNG distribution to the power plants in Papua, Indonesia. The given solution assigns one ship with $2500 \mathrm{~m}^{3}$ ship capacity, four ships with $7500 \mathrm{~m}^{3}$ ship capacity, and two ships with $23000 \mathrm{~m}^{3}$ ship capacity. The solution offers the utilization of smaller-size ship than the earlier research. It is considered to be more reliable to cope with uncertain weather in Indonesia.

Moreover, the utilization of small-size ships is considered to be more profitable in Indonesia. As shown in the economic assessment section, small-size ships utilization only requires a profit margin of USD 2.00 to become a profitable project.

\section{Acknowledgment}

The authors would like to acknowledge Lembaga Pengelola Dana Pendidikan of Ministry of Finance of Indonesia for funding this research.

\section{References}

1. Kır S, Yazgan H, Tüncel E 2017 A novel heuristic algorithm for capacitated vehicle routing problem J. Industrial Eng. Int. 2017 13(3) 323-30

2. Kumar S, Panneerselvam R 2015 A time-dependent vehicle routing problem with time windows for e-commerce supplier site pickups using genetic algorithm. Intelligent Inf. Manag. 07(04) 181-94

3. Mester D, Bräysy O 2007 Active-guided evolution strategies for large-scale capacitated vehicle routing problems Compt. and Ops. Research. 34(10) 2964-75

4. Nagata Y, Bräysy O 2009 A powerful route minimization heuristic for the vehicle routing problem with time windows Ops. Research Letters 37(5) 333-38

5. Antara G 2016 Optimasi dan Analisa Keekonomian Distribusi LNG ke Pembangkit di Wilayah Papua (Master Degree: Institut Teknologi Sepuluh Nopember)

6. Chiesa V, Frattini F 2009 Evaluation and Performance Measurement of Research And Development (Northampton: Edward Elgar)

7. Soegiono, Artana K 2006 Transportasi LNG Indonesia (Surabaya: Airlangga University Press) 